\title{
NOTAS CIENTÍFICAS \\ ATAQUE DE ATARSOCORIS BRACHIARIAE BECKER, UMA NOVA PRAGA DAS PASTAGENS EM MATO GROSSO, BRASIL ${ }^{1}$
}

\author{
MARCELO PICANÇO² ${ }^{2}$ GERMANO LEÃO DEMOLIN LEITE³, MÁRCIO C. MENDES \\ e VALDIVINO ENEDINOBORGES ${ }^{4}$
}

\begin{abstract}
RESUMO - Estudou-se o efeito da textura do solo, relevo, espécie forrageira, idade e sistema de formação da pastagem, sobre o ataque de Atarsocoris brachiariae. Não foram observadas diferenças significativas entre as espécies de forrageiras ou tipo de relevo quanto ao ataque da praga. As maiores densidades foram observadas em solos de textura arenosa, pastagens com mais de quatro anos, sistema de formação convencional e na faixa de $20-30 \mathrm{~cm}$ de profundidade. $\mathrm{O}$ ataque foi em reboleiras, e a maior densidade ocorreu na região de transição entre a área de pastagem morta e a área em que esta apresentava desenvolvimento normal.
\end{abstract}

\section{ATTACK OF ATARSOCORIS BRACHIARIAE BECKER, A NEW PEST OF PASTURELANDS IN MATO GROSSO, BRAZIL}

\begin{abstract}
The effect of soil texture, landscape, grass species, age and system of pasture formation on attack intensity of Atarsocoris brachiariae Becker was studied. No differences were found among grass species or landscape on attack intensity of this bug. Higher densities of $A$. brachiariae were observed in sandy soils, in pastures over four years old, in those with traditional formation and between 20-30 cm underground. Attack of A. brachiariae occurred in patches specially in the transition areas between dead grass and normal growing grass.
\end{abstract}

O Brasil tem um dos maiores rebanhos bovinos do mundo, criado, em sua maior parte, de forma extensiva. Este se caracteriza pela baixa tecnologia empregada, o que resulta em baixa produtividade, causada pela falta de adubação das pastagens, pela taxa de lotação, pelo uso de espécies forrageiras inadequadas (Gomide, 1980; Carvalho, 1985) e pelo ataque de pragas (Reis et al., 1980), entre outras. Dentre as pragas que atacam o sistema radicular das gramíneas, tem-se o percevejo-castanho Scaptocoris castanea (Perty, 1830) (Heteroptera: Cydnidae) (Costa \& Forti, 1993). Esta praga

\footnotetext{
${ }^{1}$ Aceito para publicação em 22 de setembro de 1998.

2 Eng. Agr., D.Sc., Dep. de Biologia Animal, UFV, CEP 36571-000 Viçosa, MG. E-mail: picanco@mail.ufv.br

${ }^{3}$ Eng., Agr., M.Sc., Dep. de Biologia Animal, UFV.

${ }^{4}$ Eng. Agr., M.Sc., EMPAER, Av. Proj. "B”, Ed. Ceres, C.P.A., CEP 78055-970 Cuiabá, MT.
} 
constitui sério problema em diversas culturas, pois determina acentuado atraso no desenvolvimento, pela sucção da seiva das raízes e pela injeção de toxinas (Gallo et al., 1988). Como resultado do ataque deste inseto, ocorre o definhamento, secagem e morte das pastagens, trazendo prejuízos aos fazendeiros (Costa \& Forti, 1993).

Observou-se, no Estado do Mato Grosso, em 1992, nos municípios de Dom Aquino, Brasnorte, Cuiabá, Pontes \& Lacerda, Porto Espiridião e Rosário Oeste, morte de pastagens atribuída ao ataque de $S$. castanea. A área de pastagens morta por esta praga, só em Dom Aquino, foi cerca de 10.000 hectares. Entretanto, em trabalho recente, Becker (1996) apontou nova espécie para ciência, o Atarsocoris brachiariae Becker, 1996 (Heteroptera: Cydnidae). Este percevejo foi responsável pela totalidade da morte das pastagens nesta região.

Para o estabelecimento de sistema de manejo desta praga, é necessária a realização de estudos sobre os fatores determinantes da intensidade do seu ataque como, também sobre a distribuição das populações desta praga. Infelizmente, são raros os estudos com tais finalidades para as espécies de percevejos subterrâneos. Assim, esta pesquisa objetivou o estudo dos fatores que afetam a intensidade de ataque de $A$. brachiariae em pastagens no estado do Mato Grosso.

Este trabalho foi realizado em Dom Aquino, MT, em abril de 1992. Os dados experimentais foram coletados nas fazendas Água Boa, Asa Branca II, Belo Horizonte, Boa Sorte, Estância do Criador, Três Irmãos, Ivan Tabora, João Augusto de Oliveira e Severino Pereira de Lima, por se localizarem em áreas distribuídas ao longo do município e possuírem características que possibilitaram o estudo dos fatores citados a seguir.

Os fatores em estudo foram: espécies forrageiras (Andropogon gayanus, Brachiaria brizantha, B. decumbens, B. humidicola, B. ruziziensis, Hyparrhenia rufa e Panicum maximum); idade da pastagem (um e quatro anos); textura do solo (arenosa ou argilosa); relevo (plano, levemente ondulado ou ondulado); e sistema de formação das pastagens (convencional com plantio a lanço ou em linha. Foram amostradas cinco pastagens neste sistema ou no sistema barreirão, com milho e soja anterior, tendo sido amostradas duas pastagens neste sistema).

O sistema convencional constitui-se de gradagem e semeadura a lanço ou em linha utilizando maquinaria. O sistema barreirão constitui-se basicamente das seguintes operações: análise química prévia do solo e calagem; aração profunda com arado de aiveca; uso de gradagem niveladora (imediatamente antes do plantio); plantio com milho; plantio com braquiária; colheita do milho e, após esta operação, isolamento do pasto por 45 a 60 dias (tempo suficiente para a sua formação). As pastagens que foram selecionadas para estudo do efeito do sistema de formação tinham mais de um ano de idade.

Em cada ponto de amostragem foram retiradas dez amostras de solo de $20 \times 20 \times 20 \mathrm{~cm}$, nas profundidades de 0-20, 20-40 e 40-60 cm. Cada amostra foi peneirada, e contou-se o número de ninfas e de adultos de $A$. brachiariae. Nos locais onde as pastagens apresentavam desenvolvimento normal, as amostras foram retiradas de forma casualizada sem restrição na casualização. Já as pastagens que apresentavam plantas mortas foram divididas em duas partes: área do foco (local onde a pastagem se encontrava morta) e área 
exterior ao foco (local onde a pastagem apresentava desenvolvimento normal). A linha de contorno do perímetro de divisa entre estas duas áreas foi considerada como ponto de referência (distância zero); as distâncias para o interior do foco foram consideradas como negativas, e as distâncias para o exterior do foco, como positivas. Foram retiradas amostras nas distâncias de $-10,-5,0,5$ e $10 \mathrm{~m}$.

Os dados foram expressos em densidade populacional de adultos e ninfas da praga $/ \mathrm{m}^{2}$, transformados em $\sqrt{(\mathrm{x}+0,5)}$ submetidos ao teste de Duncan e à análise de regressão a $\mathrm{p}<0,05$.

Não foram detectadas diferenças significativas entre as espécies de forrageiras e tipo de relevo sobre a densidade de ataque de Atarsocoris brachiariae.

As maiores densidades $\left(\mathrm{n}-\mathrm{m}^{2}\right)$ de $A$. brachiariae foram observadas em solos de textura arenosa (Tabela 1 ). O mesmo foi relatado para o $S$. castanea (Brissola et al., 1985; Costa \& Forti, 1993). Esta preferência se deve, provavelmente às condições mais aeróbicas e de menor densidade aparente dos solos de textura arenosa, visto que estes insetos têm por hábito aprofundarem-se no solo nas épocas mais secas, retornando às camadas superficiais do solo durante as chuvas (Gallo et al., 1988).

$\mathrm{O}$ ataque de $A$. brachiariae foi observado somente em pastagens com mais de quatro anos de idade (Tabela 1), as quais também estavam degradadas. É provável que este seja o tempo necessário para que estes insetos atinjam densidades populacionais capazes de causar danos observáveis às pastagens. Além disso, plantas sob estresse são mais suscetíveis ao ataque de pragas (Edwards \& Wratten, 1980). Fato similar foi observado por Costa \& Forti (1993), quanto ao ataque de $S$. castanea em pastagens formadas havia mais de cinco anos, em solo do tipo Podzólico Vermelho-Amarelo distrófico, originalmente coberto por vegetação de cerrado.

TABELA 1. Densidade populacional de Atarsocoris brachiariae em função do sistema de formação da pastagem, textura do solo e da idade da pastagem. Dom Aquino, MT, 1992.

\begin{tabular}{|c|c|c|}
\hline Sistema de formação & \multicolumn{2}{|c|}{ Insetos $/ \mathrm{m}^{2}$} \\
\hline Convencional & \multicolumn{2}{|c|}{$58,03 \mathrm{~A}$} \\
\hline Barreirão & \multicolumn{2}{|c|}{$0,00 \mathrm{~B}$} \\
\hline \multirow[t]{2}{*}{ Textura do solo } & \multicolumn{2}{|c|}{ Fases } \\
\hline & Ninfal & Adulta \\
\hline Argilosa & $2,22 \mathrm{aB}$ & $0,00 \mathrm{bB}$ \\
\hline Arenosa & $46,97 \mathrm{aA}$ & $15,03 \mathrm{bA}$ \\
\hline \multirow[t]{2}{*}{ Idade da pastagem } & \multicolumn{2}{|c|}{ Textura do solo } \\
\hline & Argilosa & Arenosa \\
\hline 1 ano & $0,00 \mathrm{aB}$ & $0,00 \mathrm{aB}$ \\
\hline Mais de 4 anos & $3,33 \mathrm{aA}$ & $14,67 \mathrm{bA}$ \\
\hline
\end{tabular}

As médias seguidas pela mesma letra minúscula na linha ou maiúsculas na coluna não diferem, entre si, pelo teste de Duncan, a $5 \%$ de probabilidade. 
Não se detectou ataque de $A$. brachiariae em pastagem formada utilizando-se sistema barreirão com milho. Já as pastagens formadas usando-se sistema convencional, apresentaram elevado ataque (Tabela 1). Este fato, possivelmente, se deva ao maior revolvimento do solo do sistema barreirão, o que ocasionou a morte dos insetos, não somente pelo efeito mecânico, mas também pela exposição aos raios solares, principalmente no caso das ninfas, por estas necessitarem de maior umidade para o desenvolvimento. Segundo Vanetti (1983), no sistema de consórcio com milho, o uso de adubação química proporciona maior fertilidade do solo e, assim, as gramíneas forrageiras suportam melhor o ataque da praga. Aliado a este fato, o $\mathrm{pH}$ menos ácido do solo no sistema barreirão pode propiciar aumento da densidade de entomopatógenos , principalmente de bactérias. Segundo Costa \& Forti (1993), nas áreas com infestação severa do percevejo-castanho, a utilização de culturas anuais durante um ou dois anos, utilizando medidas preventivas (uso de inseticidas no sulco de plantio), contribui para reduzir a população deste inseto e os custos de implantação da pastagem.

$\mathrm{O}$ ataque de $A$. brachiariae ocorreu em reboleiras (Fig. 1). Na região de transição entre a área de pastagem morta e a área em que a pastagem apresentava desenvolvimento normal (foco zero), foi onde se concentrou o maior número de insetos $/ \mathrm{m}^{2}$. Nas áreas de pastagem morta $(-5,-10)$, número de

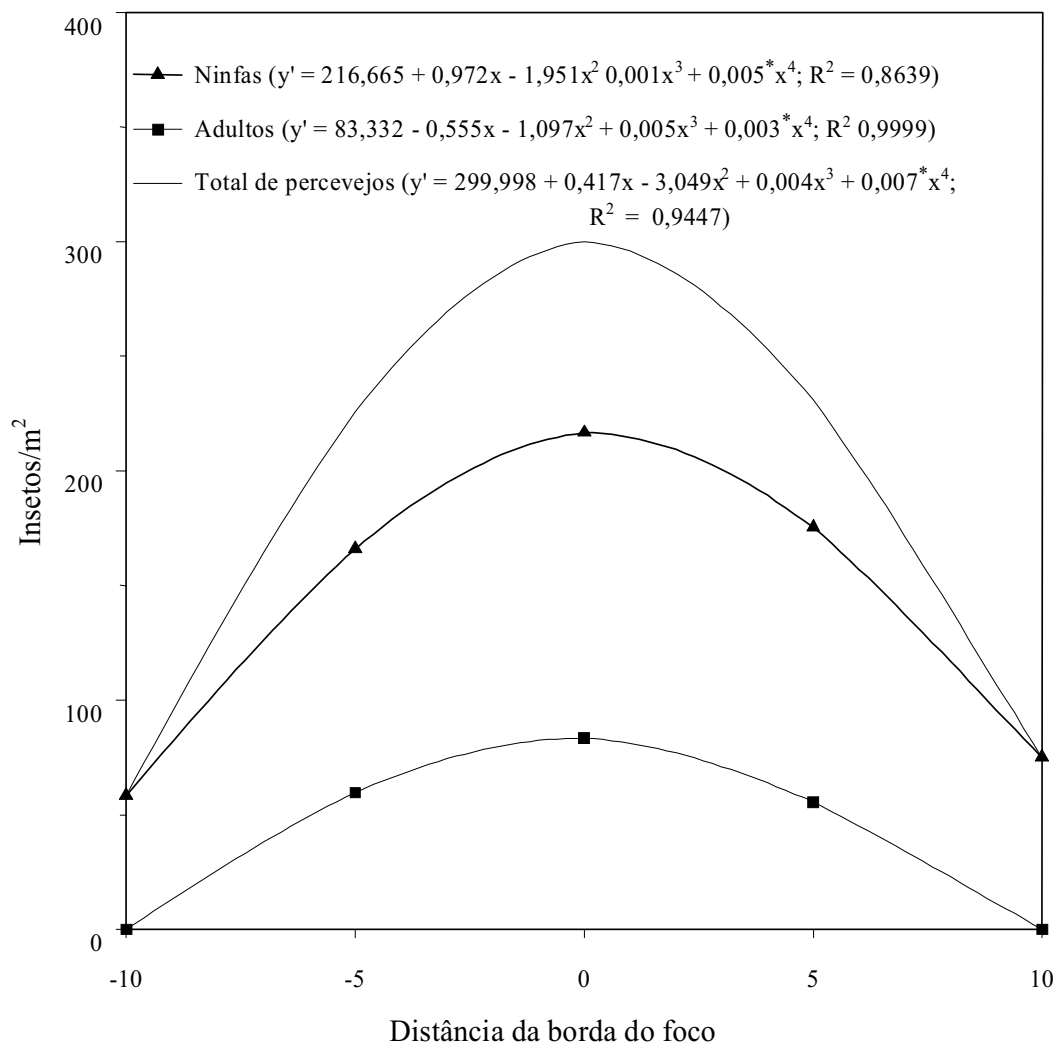

FIG. 1. Densidade populacional de Atarsocoris brachiariae ao longo do foco. Dom Aquino, MT, 1992. (*Significativo pelo teste F; p $<0,05$ ). 
insetos $/ \mathrm{m}^{2}$ foi baixo por falta de alimento e, possivelmente, por causa da emigração. Nas áreas de pastagem viva $(+5,+10)$, o número de insetos $/ \mathrm{m}^{2}$ também foi baixo, provavelmente, por estas estarem em processo inicial de colonização. Fato similar foi observado por Costa \& Forti (1993) em percevejo-castanho em pastagens.

A maior densidade de indivíduos do A. brachiariae foi encontrada na faixa de 20-30 cm de profundidade no solo (Fig. 2), provavelmente devido ao teor de umidade do solo e à faixa de temperatura do solo ótimos ao desenvolvimento desta praga no período avaliado, como observado no caso do percevejo-castanho (Vanetti, 1983). Segundo Gallo et al. (1988), nas épocas mais secas, o $S$. castanea costuma aprofundar-se no solo, procurando as regiões mais úmidas, e durante as chuvas retornam às camadas superficiais. Outro fator possível é a maior concentração de raízes das gramíneas nesta faixa de profundidade.

Assim, as maiores densidades de $A$. brachiariae são observadas em solos de textura arenosa, pastagens com mais de quatro anos e sistema de formação convencional. O maior número de indivíduos do $A$. brachiariae é encontrado

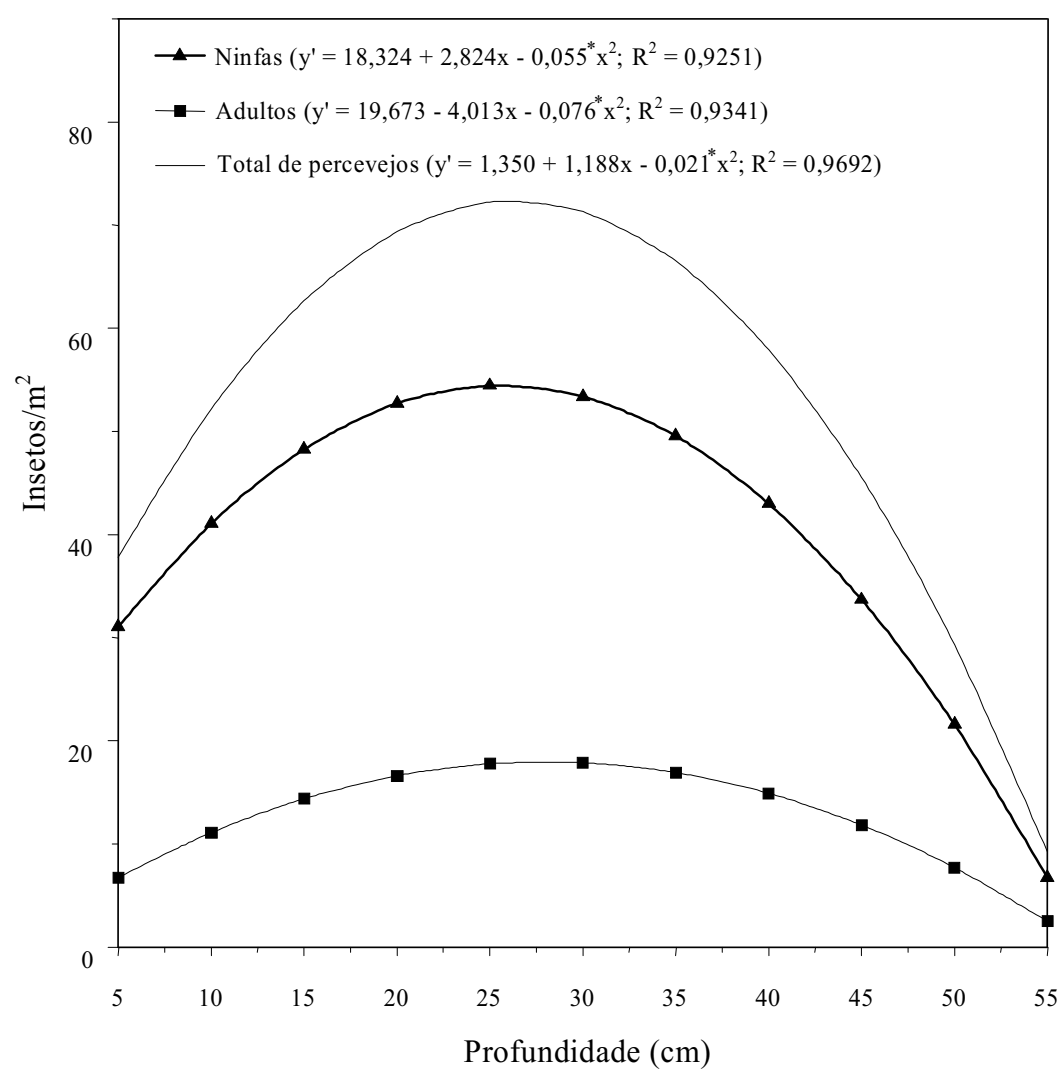

FIG. 2. Densidade populacional de Atarsocoris brachiariae por $\mathrm{m}^{2}$ ao longo do perfil do solo. Dom Aquino, MT, 1992. (*Significativo pelo teste $\mathbf{F} ; \mathbf{p}<\mathbf{0 , 0 5})$. 
na faixa de 20-30 cm de profundidade no solo. O ataque do percevejo-daspastagens é em reboleiras, com maior densidade na região de transição entre a pastagem morta e a pastagem que apresenta desenvolvimento normal. As espécies de forrageiras testadas e o tipo de relevo não parecem afetar a densidade populacional.

\section{AGRADECIMENTOS}

Aos técnicos da EMPAER-MT do município de Dom Aquino, MT, e em especial ao Técnico Agrícola João Bosco Pereira, pela valiosa colaboração na condução deste trabalho.

\section{REFERÊNCIAS}

BECKER, M. Uma nova espécie de percevejo-castanho (Heteroptera: Cydnidae: Scaptocorinae) praga de pastagens do Centro-Oeste do Brasil. Anais da Sociedade Entomológica do Brasil, Londrina, v.25, n.1, p.95-102, 1996.

BRISSOLA, A.D.; FURTADO, E.L.; CARDIM, C.F.; KUWAMOTO, O.S. Ocorrência do percevejo castanho - Scaptocoris castanea Perty, 1830 - em bananal na região litorânea do estado de São Paulo. O Biológico, São Paulo, v.51, n.5, p.135-137, 1985.

CARVALHO, M.M. de. Melhoramento da produtividade das pastagens através da adubação. Informe Agropecuário, Belo Horizonte, v.11, n.132, p.23-32, 1985.

COSTA, C.; FORTI, L.C. Ocorrência de Scaptocoris castanea, Perty, 1830, em pastagens cultivadas no Brasil. Pesquisa Agropecuária Brasileira, Brasília, v.28, n.8, p.977-979, 1993.

EDWARDS, P.J.; WRATTEN, S.D. Ecology of insect-plant interactions. London: Edward Arnold, 1980. 171p.

GALLO, D.; NAKANO, O.; SILVEIRA NETO, S.; CARVALHO, R.P.L.; BATISTA, G.C. de; BERTI FILHO, E.; PARRA, J.R.P.; ZUCCHI, R.A.; ALVES, S.B.; VENDRAMIM, J.D. Manual de entomologia agrícola. São Paulo: Agronômica Ceres, 1988. 649p.

GOMIDE, J.A. Fatores de rebrota das gramíneas forrageiras. Informe Agropecuário, Belo Horizonte, v.6, n.71, p.3-6, 1980.

REIS, P.R.; MELO, L.A. da S.; BOTELHO, W. Pragas das pastagens. Informe Agropecuário, Belo Horizonte, v.6, n.71, p.47-54, 1980.

VANETTI, F. Entomologia agrícola. Viçosa: UFV, 1983. 355p. 